\title{
Microvascular Permeability to Albumin and Glomerular Filtration Rate in Diabetic and Normal Children
}

\author{
J. Brøchner-Mortensen, J. Ditzel, C. E. Mogensen, and P. Rødbro \\ Department of Clinical Physiology, Department of Medicine (Section of Endocrinology), and Department of Paediatrics, Aalborg Sygehus, \\ and Second University Clinic of Internal Medicine, Kommunehospitalet, Århus, Denmark
}

\begin{abstract}
Summary. In order to examine the permeability of microvessels in diabetic children, the glomerular filtration rate, urinary excretion rates of albumin and $\beta_{2}$-microglobulin, intravascular mass of albumin, and transcapillary escape rate of albumin were studied in 26 diabetic children without clinical signs of microangiopathy (age: 7-14 years; duration of disease: 3-14 years). Similar measurements were made in 28 healthy school children (age: 8-14 years). Mean glomerular filtration rate in the diabetic children was higher than in the normal children (138 versus $109 \mathrm{ml} / \mathrm{min}$ per $1.73 \mathrm{~m}^{2}, \mathrm{p}<0.01$ ). Urinary excretion rates of albumin and $\beta_{2}$-microglobulin did not differ in diabetics. Mean intravascular albumin mass in the diabetic girls $(1.64 \mathrm{~g} / \mathrm{kg}$ body weight $)$ was lower $(\mathrm{p}<0.01)$ than in the diabetic boys $(1.89 \mathrm{~g} / \mathrm{kg}$ body weight $)$ and also lower $(p<0.02)$ than in the normal girls $(1.94 \mathrm{~g} / \mathrm{kg}$ body weight). Mean transcapillary escape rate of albumin in the twenty diabetics with duration of diabetes less than 10 years $(7.14 \% / \mathrm{h})$ was lower $(\mathrm{p}<0.01)$ than that in normal children $(8.90 \% / h)$; the escape rate showed a positive correlation with duration of diabetes $(r=0.47 ; p<0.02)$. Thus glomerular filtration rate in diabetic children is elevated to the same extent as in adult short-term juvenile diabetics while the permeability of the glomerular membrane to macromolecules is normal. Interpretation of the results on intravascular albumin mass and transcapillary escape rate of albumin requires further investigation.
\end{abstract}

Key words: Diabetes mellitus, glomerular filtration rate, microvascular permeability, plasma volume, proteinuria, serum albumin, transcapillary escape rate of albumin, $\beta_{2}$-microglobulin.
An early lesion in diabetic microangiopathy, involving most microvessels of the body, is an ultrastructural thickening of the capillary basement membrane. The morphological thickening is not measurable in the glomerular capillaries at the onset of diabetes but is detectable after one and a half year's duration, whereafter the basement membrane thickens with increasing duration of disease [14]. The time course of basement membrane changes in other microvessels of the body is not fully clarified.

Investigations on the permeability of the microvessels to macromolecules have been performed in newly diagnosed and short-term diabetics $[11,13$, $17,18]$ mainly to test whether changes in permeability precede or follow the basement membrane thickening. Renal glomerular permeability to macromolecules has been assessed from the urinary excretion rate of albumin, $u_{a b}$, and the overall microvascular permeability to plasma proteins has been evaluated from the transcapillary escape rate of albumin (TER) i. e. fraction of intravascular mass of albumin that passes to the extravascular space per unit time. Studies in adult diabetics under poor metabolic control and after exercise loads suggest that an increased extravasation of plasma proteins both precedes [11, 18] and accompanies [13] morphologically measurable changes of the microvessels. On the other hand, both $u_{\mathrm{alb}}$ and TER have been reported normal in adult short-term diabetics examined during rest and in good metabolic control $[11,17,18]$.

Hitherto, studies on the permeability of the microvessels to macromolecules have not been reported in diabetic children. We present here a study in which TER, $u_{\mathrm{alb}}$, plasma volume, serum albumin, glomerular filtration rate and urinary excretion rate of $\beta_{2}$ microglobulin were determined, and the values compared to those in normal children. 
Table 1. Clinical data in 26 diabetic and 28 normal children

\begin{tabular}{|c|c|c|c|c|c|c|c|c|c|c|c|c|}
\hline & \multicolumn{2}{|l|}{ Number } & \multicolumn{2}{|c|}{$\begin{array}{l}\text { Age of } \\
\text { females (years) }\end{array}$} & \multicolumn{2}{|c|}{$\begin{array}{l}\text { Age of } \\
\text { males (years) }\end{array}$} & \multicolumn{2}{|c|}{ Height $(\mathrm{cm})$} & \multicolumn{2}{|c|}{$\begin{array}{l}\text { Body weight } \\
\text { (kg) }\end{array}$} & \multicolumn{2}{|c|}{$\begin{array}{l}\text { Surface area } \\
\left(\mathrm{m}^{2}\right)\end{array}$} \\
\hline & females & males & mean & range & mean & range & mean & range & mean & range & mean & range \\
\hline Diabetics & 17 & 9 & 11.5 & $7-14$ & 12.4 & $10-14$ & 149.7 & $121-174$ & 39.9 & $23-69$ & 1.29 & $0.90-1.82$ \\
\hline Controls & 13 & 15 & 11.5 & $10-13$ & 12.0 & 8-14 & 152.5 & $135-174$ & 42.4 & $30-66$ & 1.34 & $1.10-1.77$ \\
\hline
\end{tabular}

Table 2. Clinical data in 26 diabetic children ( 17 females, 9 males)

\begin{tabular}{|c|c|c|c|c|c|c|}
\hline & \multicolumn{2}{|c|}{ Duration of diabetes (years) } & \multicolumn{2}{|c|}{ Plasma glucose $(\mathrm{mmol} / \mathrm{l})$} & \multicolumn{2}{|c|}{ Standard bicarbonate $(\mathrm{mmol} / \mathrm{l})$} \\
\hline & $\overline{\text { mean }}$ & range & mean & range & mean & range \\
\hline Females & 6.0 & $3-11$ & 12.5 & $5.8-19.2$ & 23.5 & $21.3-27.1$ \\
\hline Males & 8.4 & $3-14$ & 14.6 & $8.5-18.2$ & 22.2 & $19.1-24.1$ \\
\hline
\end{tabular}

Standard bicarbonate (mmol/1) in 28 normal children: Mean: 23.6; Range: 21.8-25.6

\section{Material}

Twenty-six ambulatory children (17 girls and 9 boys), aged 7-14 years, with insulin dependent diabetes mellitus for 3-14 years participated in the study. Twelve of the children had a daily intake of $1000 \mathrm{mg}$ phosphorus. The daily intake of phosphorus was $2000 \mathrm{mg}$ in the remaining fourteen children. None of the children had clinical signs of microangiopathy, i. e, retinopathy or nephropathy. Serum creatinine concentration was normal and proteinuria, tested for by Albustix ${ }^{\mathbb{1}}$, was not detected. Duration of diabetes together with values of standard bicarbonate and fasting venous plasma glucose on the day of investigation are given in Table 2 . All children had increased plasma glucose concentrations, but five of 17 girls had lower values than the lowest level in boys. Four of 9 boys, but only two of 17 girls, had a decreased standard bicarbonate compared to the lowest level in the controls. $\mathrm{pH}$ of capillary blood was normal (range 7.36-7.44).

Twenty-eight healthy school children (13 girls and 15 boys), aged 8-14 years, served as controls. Clinical data in the 26 diabetic and 28 normal children are given in Table 1 . Informed consent was obtained from all parents, for both normal and diabetic children.

\section{Methods}

All children were studied in the supine position in the morning between nine and $12 \mathrm{am}$. after at least a $12 \mathrm{~h}$ fast and a $30-60 \mathrm{~min}$ rest period, preceded by voiding urine. The bladder was again emptied at the end of the study and urine collected. During the examination $200 \mathrm{ml}$ water was given by mouth. The usual morning-dose of insulin was deferred until the end of the test.

Concentration of albumin in serum, $S_{\text {alb }}(\mathrm{g} / \mathrm{l})$, was measured in one sample at the start of examination by immunoelectrophoresis, and total plasma protein concentration, $P_{P}(g / 1)$, was read refractometrically with a TS Meter (American Opticai Corp.), the precision of this method being $0.5 \%$ (coefficient of variation). Concentration of globulins in plasma, $\mathrm{P}_{\text {glob }}(\mathrm{g} / \mathrm{l})$, was calculated as $\mathrm{P}_{\mathrm{P}}-\mathrm{S}_{\text {alb }}$.

Transcapillary escape rate of albumin, TER, was determined according to the method of Parving and Gyntelberg (16). [ $\left.{ }^{125} \mathrm{I}\right]-$ labelled albumin for metabolic purposes (code MIAK, Institute for Atomic Energy, Kjeller, Norway) was used as tracer, and 8 venous plasma samples were drawn during the first 60 minutes after IV injection of $2-4 \mu \mathrm{Ci}\left[{ }^{125} \mathrm{I}\right]$ albumin. The radioactivity in each plasma sample was expressed in relation to $P_{P}\left(\mathrm{cpm} / P_{\mathrm{P}}\right)$ to avoid errors due to accidental plasma volume changes. TER was calculated as the rate constant (determined by the method of least squares) of the monoexponential decrease in "specific" plasma activity during the first 60 minutes after injection, and expressed as per cent of the intravascular mass of albumin that passes to the extravascular compartments per hour. Since TER is calculated as a rate constant (dimension: time ${ }^{-1}$ ) the value of TER is the same whether the radioactivity in the plasma samples is expressed in relation to total plasma protein concentration or plasma albumin concentration. The use of total plasma protein concentration instead of plasma albumin concentration was chosen due to the simplicity and high precision by which total plasma protein concentration is determined by refractometry.

Plasma volume, PV, was calculated as the ratio between the injected amount of $\left[{ }^{125}\right]$ albumin and the plasma activity concentration of $\left[{ }^{125} \mathrm{I}\right]$ albumin at time zero as determined by extrapolation of the monoexponential disappearance curve. PV was expressed as $\mathrm{ml} / \mathrm{kg}$ body weight.

Intravascular mass of albumin, IVM, was calculated as PV times $S_{\text {alb }}$ and expressed as $\mathrm{g} / \mathrm{kg}$ body weight.

Urinary excretion rates of albumin, $\mathrm{u}_{\mathrm{alb}}(\mu \mathrm{g} / \mathrm{min})$, and $\beta_{2}$-microglobulin, $\mathrm{u}_{\beta_{2}}(\mathrm{ng} / \mathrm{min})$, were determined by radioimmunoassays (6, 8, Pharmacia diagnostics Phadebas beta-2-microtest-kit) on the timed and measured urine collection. Significant degradation of $\beta_{2}$-microglobulin may occur in stored urine samples with $\mathrm{pH} \leqslant 5.5$. Only the $\mathrm{u}_{\beta_{2}}$ values of 18 normal children and 21 diabetic children with urine $\mathrm{pH}>5.5$ are presented here. All values were corrected to $1.73 \mathrm{~m}^{2}$ surface area.

Glomerular filtration rate, GFR $\left(\mathrm{ml} / \mathrm{min}\right.$ per $\left.1.73 \mathrm{~m}^{2}\right)$, was determined from the total $\left[{ }^{51} \mathrm{Cr}\right.$ ] EDTA plasma clearance, measured by a simplified single injection method (2), over 2 hours after the IV injection of $3 \mu \mathrm{Ci}\left[{ }^{51} \mathrm{Cr}\right]$ EDTA per $\mathrm{kg}$ body weight (maximum $100 \mu \mathrm{Ci}$ ). The minor inaccuracy of the clearance versus GFR was corrected for (3).

Venous plasma glucose concentration was measured by an autoanalyser technique at the start and end of examination, and $\mathrm{pH}$ of capillary blood and standard bicarbonate were determined by conventional laboratory techniques.

\section{Statistical Analysis}

For the analysis, the difference in phosphorus intake could be ignored since unpublished data in 43 diabetic children from our departments did not show any difference between children receiving $1000 \mathrm{mg}$ and $2000 \mathrm{mg}$ phosphorus daily, with respect to the parameters, we have measured.

There were more female diabetics than controls $(65 \%$ versus $46 \%$, Table 1 ), and the distribution of ages for each sex within and between diabetics and controls showed minor differences. In order 
to make a reliable comparison between diabetics and controls, the above mentioned differences made it necessary in the first place to test whether any of the measured parameters showed a significant linear correlation with age. This was not the case. Consequently, differences in each parameter between sexes within diabetics and controls could be tested without regard to age. In those instances where significant differences between sexes were found, either in the diabetics or in the controls, the comparison between diabetics and controls was done for each sex. Otherwise, the comparisons were done without regard to sex. Mann-Whitney's non parametric test was used for all comparisons. Linear correlations between each measured parameter and venous plasma glucose concentration and duration of disease, respectively, were calculated for the diabetic children. Linear correlations between plasma volume and transcapillary escape rate of albumin in the diabetic and normal children were also tested.

\section{Results}

Individual values of transcapillary escape rate of albumin (TER) are shown in Figure 1. TER showed a significant positive linear correlation with duration of diabetes $(r=0.47 ; p<0.02)$. According to the calculated regression equation of TER on duration of diabetes, TER in the diabetics attained the same level as the mean value in the controls at 10 years duration of diabetes. In the 20 diabetics with duration of diabetes less than 10 years the mean value $\pm \mathrm{SD}: 7.14 \pm 2.17(\% / \mathrm{h})$ was significantly lower $(\mathrm{p}<0.01)$ than that in the controls: $8.90 \pm 1.65(\% /$ h).

There was no significant correlation between plasma volume and TER either in the diabetics or in the controls. As shown in Figure 2 plasma volume was significantly lower in the diabetics $(p<0.01)$.

The only significant differences between sexes were found in the diabetics with respect to concentration of albumin in serum $\left(\mathrm{S}_{\mathrm{alb}}\right)$, intravascular mass of albumin (IVM) and concentration of globulins in plasma $\left(\mathbf{P}_{\text {glob }}\right) . \mathrm{S}_{\mathrm{alb}}$ and IVM, which were lower in females $(p<0.01)$ and $P_{\text {glob }}$, which was higher in females $(p<0.01)$. Individual values of $S_{\text {alb }}$ and IVM together with means \pm SD for each sex in the two groups are shown in Figure $3 . \mathrm{S}_{\mathrm{aib}}$ in the diabetic girls was significantly lower than in the normal girls, whereas there was no significant difference between boys in the two groups. The same pattern was found for IVM and $\mathrm{P}_{\text {glob }}$. There was no significant difference between total plasma protein concentration in diabetics: $64.7 \pm 3.5(\mathrm{~g} / \mathrm{l})$ and controls: $63.4 \pm 2.9(\mathrm{~g} / \mathrm{l})$.

Figure 4 demonstrates that the mean value of glomerular filtration rate was significantly increased in the diabetic children, by $27 \%$. The same figure shows that there was no significant difference between diabetics and controls with respect to urinary excretion rates of albumin $\left(\mathrm{u}_{\mathrm{abb}}\right)$ and $\beta_{2}$-microglobulin $\left(\mathrm{u}_{\beta_{2}}\right)$. The given logarithmic mean values, of $\mathrm{u}_{\mathrm{alb}}$ and $\mathrm{u}_{\beta_{2}}$ correspond to $6.0 \mu \mathrm{g} / \mathrm{min}$ per $1.73 \mathrm{~m}^{2}$ and

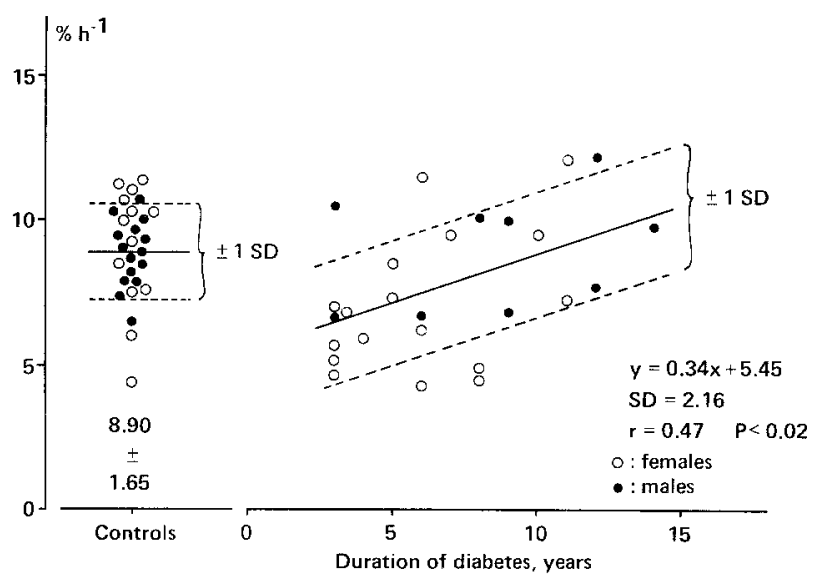

Fig. 1. Individual values of transcapillary escape rate of albumin for both sexes in 28 normal children and 26 diabetic children. The figures in the left part indicate mean value $\pm \mathrm{SD}$ of the controls. The regression line of transcapillary escape rate of albumin on duration of diabetes $(y=0.34 x+5.45)$ is shown in the right part

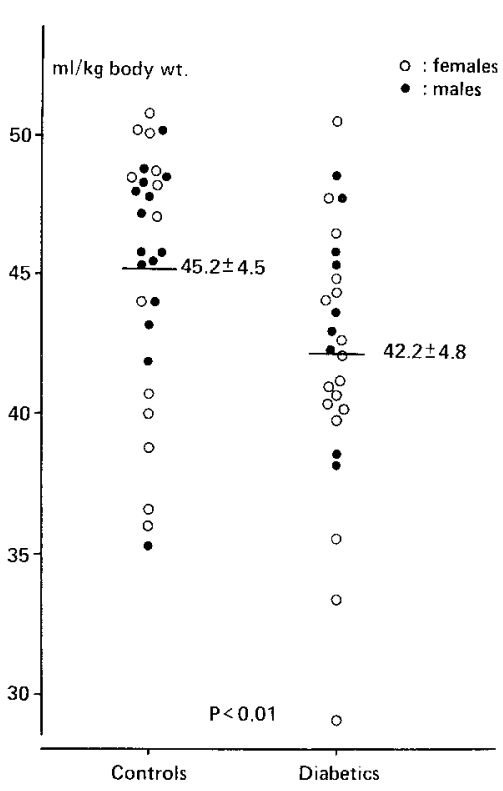

Fig. 2. Individual values of plasma volume for both sexes in 28 normal children and 26 diabetic children. Mean values \pm SD are shown

$74.1 \mathrm{ng} / \mathrm{min}$ per $1.73 \mathrm{~m}^{2}$, respectively, in the diabetic children. The corresponding figures in normal children were $8.3 \mu \mathrm{g} / \mathrm{min}$ per $1.73 \mathrm{~m}^{2}$ and $56.2 \mathrm{ng} / \mathrm{min}$ per $1.73 \mathrm{~m}^{2}$.

Except for the transcapillary escape rate of albumin versus duration of diabetes, no other correlations were significant.

\section{Discussion}

In the present study the diabetic and normal children were comparable with respect to height, body weight and surface area, but there was a difference between 
the two groups with respect to relative number of subjects of either sex and their age distribution (cf. Table 1). None of the measured parameters correlated with age, and the difference between sexes in the diabetics with respect to plasma albumin parameters (cf. Fig. 3) was taken into consideration in the analysis. Therefore, we assume that the differences found between diabetics and controls are real.

In adult short-term juvenile diabetics in a good metabolic state TER has been reported to be normal $[17,18]$, whereas it has been found significantly increased during poor metabolic control [18]. Compared to the results in normal children the present investigation showed that TER was decreased in diabetic children with duration of diabetes less than 10 years. In comparison with adult diabetics, this finding is unexpected since most of the diabetic children were in relatively poor metabolic control as
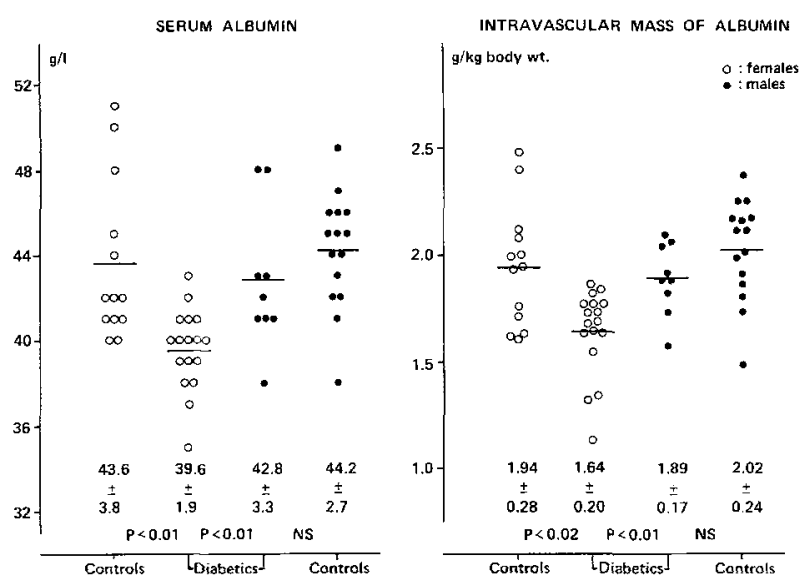

Fig. 3. Individual values of albumin concentration in serum and intravascular mass of albumin for each sex in normal children (13 females, 15 males) and diabetic children (17 females, 9 males). Mean values $\pm \mathrm{SD}$ are shown judged from the levels of fasting plasma glucose. A positive correlation between TER and plasma volume (PV) has recently been demonstrated in adult non-diabetics and short-term diabetics suggesting a change in microvascular permeability with changing plasma volume [17]. Whether such a mechanism could explain the decreased TER in diabetic children via their decreased PV is uncertain. Anyway, no positive correlation between TER and PV could be demonstrated in the present study. Whether the association between the rising TER and duration of diabetes (cf. Fig. 1) can be interpreted as a consequence of a time related change of the microvascular basement membrane is also uncertain, as long as data on the time course of ultrastructural changes of the microvessels in diabetic children are unavailable.

In normal children it has been reported that there is no difference between the two sexes [7] with respect to concentration of albumin in serum $\left(\mathrm{S}_{\mathrm{alb}}\right)$ and intravascular mass of albumin (IVM). Our results are in accordance. In the diabetic children, however, both $\mathrm{S}_{\mathrm{alb}}$ and IVM were significantly lower in girls than in boys, and both parameters in the diabetic girls were significantly lower than those in the normal girls. The minor differences between girls and boys with respect to duration of diabetes and metabolic control (cf. Table 2) can hardly explain these sex differences. Certainly, future investigations on protein metabolism with determination of the synthesis rate and fractional catabolic rate of albumin together with the distribution of albumin between intra- and extravascular compartments should be done in diabetic and normal children to elucidate the discrepancies within and between the two groups.

Considering the relatively poor metabolic control of the diabetic children (typical for diabetes in childhood), the present finding of normal urinary excretion rates of albumin $\left(\mathrm{u}_{\mathrm{alb}}\right)$ and $\beta_{2}$-microglobulin $\left(\mathrm{u}_{\beta_{2}}\right)$
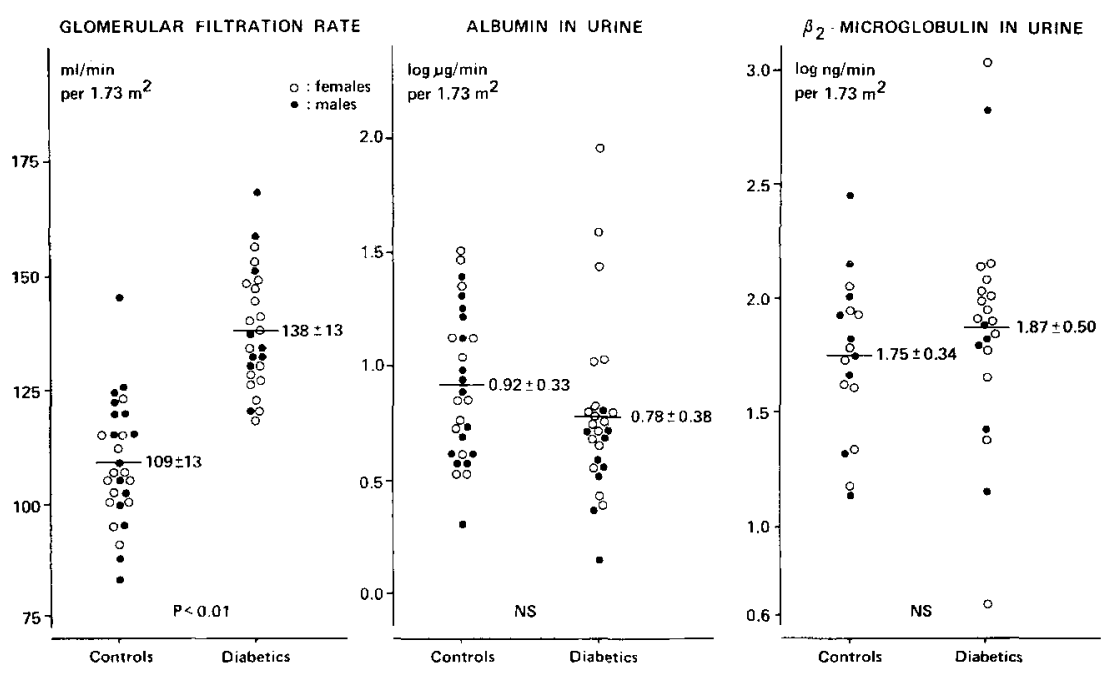

Fig. 4. Individual values of glomerular filtration rate and urinary excretion rates of albu$\min$ and $\beta_{2}$-microglobulin for both sexes in 28 normal children and 26 diabetic children. Mean values \pm SD are shown 
differs from that in adult short-term diabetics (examined during poor metabolic control) where both parameters have been found significantly increased [18]. Our results, which correspond to normal values of $u_{\mathrm{alb}}$ and $\mathbf{u}_{\beta_{2}}$ reported in adult short-term diabetics in a good metabolic control $[11,18]$, suggest that the tubular reabsorption of protein is unchanged [19] and that the transport rate of albumin through the glomerular basement membrane, at least, is not increased in diabetic children. In contrast to TER (which reflects the permeability of the overall microvasculature) $u_{\mathrm{alb}}$ did not correlate with duration of diabetes. These findings do not disagree, since the glomerular capillaries only constitute a very small part of the microvessels in the whole body, and only a small fraction of the filtered albumin is excreted in the final urine.

In several studies in adult short-term juvenile diabetics the glomerular filtration rate (GFR) has been found significantly increased by $25-30 \%$ compared to mean values in normal controls $[1,4,5,9$, 10]. A similar increase was found in the present study and in previously published investigations in diabetic children $[20,21]$. The following hypotheses have been proposed as an explanation for the increased GFR in diabetics: An increased total area of the glomerular membrane, and/or an elevated effective glomerular filtration pressure $[12,15]$.

The most unexpected findings of the present study are 1) a decreased transcapillary escape rate of albumin in children with duration of diabetes less than 10 years and an increasing escape rate with increasing duration of diabetes, and 2) a lower albumin concentration in serum and a lower intravascular mass of albumin in diabetic girls compared to normal girls and diabetic boys. Interpretation of these results needs further investigation.

\section{References}

1. Brøchner-Mortensen, J.: Glomerular filtration rate and extracellular fluid volumes during normoglycemia and moderate hyperglycemia in diabetics. Scand. J. Clin. Lab. Invest. 32, 311-316 (1973)

2. Brøchner-Mortensen, J., Haahr, J., Christoffersen, J.: A simple method for accurate assessment of the glomerular filtration rate in children. Scand. J. Clin. Lab. Invest. 33, 139-143 (1974)

3. Brøchner-Mortensen, J., Rohbrandt, K., Lauritzen, R. B.: Precision of single injection $\left[{ }^{51} \mathrm{Cr}\right]$ EDTA plasma clearance and endogenous creatinine clearance determinations in children. Scand. J. Clin. Lab. Invest. 37, 625-629 (1977)

4. Ditzel, J., Junker, K.: Abnormal glomerular filtration rate, renal plasma flow, and renal protein excretion in recent and short-term diabetics. Br. Med. J. 1972 II, 13-19

5. Ditzel, J., Schwartz, M.: Abnormally increased glomerular filtration rate in short-term insulin-treated diabetic subjects. Diabetes 16, 264-267 (1967)
6. Evrin, P.-E., Peterson, P. A., Wide, L., Berggaard, J.: Radioimmunoassay of $\beta_{2}$-microglobulin in human biological fluids. Scand. J. Clin. Lab. Invest. 28, 439-444 (1971)

7. Krasilnikoff, P. A.: Albumin metabolism in normal mature and premature children (Thesis). Copenhagen, Århus, Odense: FADL's Forlag 1975

8. Miles, D. W., Mogensen, C. E., Gundersen, H. J.: Radioimmunoassay for urinary albumin using a single antibody. Scand. J. Clin. Lab. Invest. 26, 5-11 (1970)

9. Mogensen, C. E.: Kidney function and glomerular permeability to macromolecules in early juvenile diabetes. Scand. J. Clin. Lab. Invest. 28, 79-90 (1971)

10. Mogensen, C. E.: Glomerular filtration rate and renal plasma flow in short-term and long-term juvenile diabetes mellitus. Scand. J. Clin. Lab. Invest. 28, 91-100 (1971)

11. Mogensen, C. E.: Urinary albumin excretion in early and longterm juvenile diabetes. Scand. J. Clin. Lab. Invest. 28, 183-193 (1971)

12. Mogensen, C. E.: Kidney function and glomerular permeability to macromolecules in juvenile diabetes with special reference to early changes. Dan. Med. Bull. 19 [Suppl. 3], 1-40 (1972)

13. Mogensen, C. E., Vittinghus, E.: Urinary albumin excretion during exercise in juvenile diabetes. A provocation test for early abnormalities. Scand. J. Clin. Lab. Invest. 35, 295-300 (1975)

14. Østerby, R.: Early phases in the development of diabetic glomerulopathy. Acta Med. Scand. [Suppl.] 574, 1-80 (1975)

15. Østerby, R., Gundersen, H. J.: Glomerular size and structure in diabetes mellitus. I. Early abnormalities. Diabetologia 11, 225-229 (1975)

16. Parving, H.-H., Gyntelberg, F.: Transcapillary escape rate of albumin and plasma volume in essential hypertension. Circ. Res. 32, 643-651 (1973)

17. Parving, H.-H., Munkgaard Rasmussen, S.: Transcapillary escape rate of albumin and plasma volume in short- and longterm juvenile diabetics. Scand. J. Clin. Lab. Invest. 32, 81-87 (1973)

18. Parving, H.-H., Noer, I., Deckert, T., Evrin, P.-E., Nielsen, S. L., Lyngsøe, J., Mogensen, C. E., Rørth, M., Svendsen, P. Aa., Trap-Jensen, J., Lassen, N. A.: The effect of metabolic regulation on microvascular permeability to small and large molecules in short-term juvenile diabetics. Diabetologia 12, 161-166 (1976)

19. Peterson, P. A., Evrin, P.-E., Borggaard, I.: Differentiation of glomerular, tubular, and normal proteinuria: Determinations of urinary excretion of beta-2-microglobulin, albumin, and total protein. J. Clin. Invest. 48, 1189-1198 (1969)

20. Stalder, G., Schmid, R.: Severe functional disorders of glomerular capillaries and renal hemodynamics in treated diabetes mellitus during childhood. Pediatr. Ann. 193, 129-138 (1959)

21. Stalder, G., Schmid, R., Wolff, M.: Funktionelle Mikroangiopathie der Nieren beim behandelten Diabetes mellitus im Kindesalter. Dtsch. Med. Wochenschr. 85, 346-350 (1960)

Received: May 1978

and in revised form: January 23, 1979

Dr. J. Brøchner-Mortensen

Department of Clinical Physiology

Aalborg Sygehus, afsnit SYD

Postbox 365

DK-9100 Aalborg

Denmark 